\title{
Obesity and Mortality Among Patients Diagnosed With COVID-19: A Systematic Review and Meta-Analysis
}

\begin{abstract}
Tahmina Nasrin Poly 1,2,3, Md. Mohaimenul Islam 1,2,3, Hsuan Chia Yang 1,2,3, Ming Chin Lin 1,4,5,6,7, Wen-Shan Jian ${ }^{8}$, Min-Huei Hsu ${ }^{9}$ and Yu-Chuan Jack Li 1,2,3,10,11*

${ }^{1}$ Graduate Institute of Biomedical Informatics, College of Medical Science and Technology, Taipei Medical University, Taipei, Taiwan, ${ }^{2}$ International Center for Health Information Technology (ICHIT), Taipei Medical University, Taipei, Taiwan, ${ }^{3}$ Research Center of Big Data and Meta-Analysis, Wan Fang Hospital, Taipei Medical University, Taipei, Taiwan, ${ }^{4}$ Department of Neurosurgery, Shuang Ho Hospital, Taipei Medical University, Taipei, Taiwan, ${ }^{5}$ Professional Master Program in Artificial Intelligence in Medicine, Taipei Medical University, Taipei, Taiwan, ${ }^{6}$ Research Center for Artificial Intelligence in Medicine, Taipei Medical University, Taipei, Taiwan, ${ }^{7}$ Taipei Neuroscience Institution, Taipei Medical University, Taipei, Taiwan, ${ }^{8}$ School of Health Care Administration, Taipei Medical University, Taipei, Taiwan, ${ }^{9}$ Graduate Institute of Data Science, Taipei Medical University, Taipei, Taiwan, ${ }^{10}$ Department of Dermatology, Wan Fang Hospital, Taipei, Taiwan, ${ }^{11}$ TMU Research Center of Cancer Translational Medicine, Taipei Medical University, Taipei, Taiwan
\end{abstract}

Coronavirus disease 2019 (COVID-19) has already raised serious concern globally as the number of confirmed or suspected cases have increased rapidly. Epidemiological

\section{OPEN ACCESS}

Edited by:

Hend Mansoor

Hamad Bin Khalifa University, Qatar

Reviewed by:

Wondimeneh Shiferaw,

Debre Berhan University, Ethiopia

Makan Pourmasoumi,

Guilan University of Medical

Sciences, Iran

*Correspondence:

Yu-Chuan Jack L jack@tmu.edu.tw; jaak88@gmail.com

Specialty section:

This article was submitted to Family Medicine and Primary Care,

a section of the journal

Frontiers in Medicine

Received: 21 October 2020

Accepted: 06 January 2021

Published: 05 February 2021

Citation:

Poly TN, Islam MM, Yang HC, Lin MC, Jian W-S, Hsu M-H and Jack Li Y-C (2021) Obesity and Mortality Among Patients Diagnosed With COVID-19: A Systematic Review and Meta-Analysis. Front. Med. 8:620044. doi: 10.3389/fmed.2021.620044 studies reported that obesity is associated with a higher rate of mortality in patients with COVID-19. Yet, to our knowledge, there is no comprehensive systematic review and meta-analysis to assess the effects of obesity and mortality among patients with COVID19. We, therefore, aimed to evaluate the effect of obesity, associated comorbidities, and other factors on the risk of death due to COVID-19. We did a systematic search on PubMed, EMBASE, Google Scholar, Web of Science, and Scopus between January 1, 2020, and August 30, 2020. We followed Cochrane Guidelines to find relevant articles, and two reviewers extracted data from retrieved articles. Disagreement during those stages was resolved by discussion with the main investigator. The random-effects model was used to calculate effect sizes. We included 17 articles with a total of 543,399 patients. Obesity was significantly associated with an increased risk of mortality among patients with COVID-19 (RR adjust: 1.42 (95\% Cl: 1.24-1.63, $p<0.001)$. The pooled risk ratio for class I, class II, and class III obesity were 1.27 (95\%Cl: 1.05-1.54, $p=0.01), 1.56$ (95\%Cl: 1.11-2.19, $p<0.01)$, and 1.92 (95\% Cl: 1.50-2.47, $p<0.001)$, respectively). In subgroup analysis, the pooled risk ratio for the patients with stroke, CPOD, CKD, and diabetes were 1.80 (95\%Cl: 0.89-3.64, $p=0.10), 1.57$ (95\% Cl: 1.57-1.91, $p<0.001$ ), 1.34 (95\% Cl: 1.18-1.52, $p<0.001)$, and 1.19 (1.07-1.32, $p=0.001)$, respectively. However, patients with obesity who were more than 65 years had a higher risk of mortality (RR: 2.54; 95\%Cl: 1.62-3.67, $p<0.001$ ). Our study showed that obesity was associated with an increased risk of death from COVID-19, particularly in patients aged more than 65 years. Physicians should aware of these risk factors when dealing with patients with COVID-19 and take early treatment intervention to reduce the mortality of COVID-19 patients.

Keywords: COVID-19, SARS-CoV-2, obesity, body mass index (BMI), mortality 


\section{INTRODUCTION}

\section{Rationale}

The outbreak of coronavirus disease 2019 (COVID-19), caused by severe acute respiratory coronavirus 2 (SARS-CoV-2), has spread globally and created mounting concern (1). Healthcare organizations and providers are trying to find solutions to reduce the spread of disease and fatality rates. The rapid increase in the number of cases has created an unbearable burden on the healthcare system, especially in developing counties where healthcare systems are more fragile $(2,3)$. Early diagnosis of severe patients is essential to improve patient conditions and reduce mortality. Earlier classification of mild and severe COVID-19 patients could facilitate the proper utilization of limited resources (4). Multiple studies reported changes in several laboratory parameters [(e.g., the number of lymphocytes, Creactive protein (CRP), interleukin-6 (IL-6), and erythrocyte sedimentation rates (ESR)] in the COVID-19 patients, but data are not sufficient to show their correlation according to severity and mortality $(5,6)$. Therefore, finding an appropriate risk factor is essential to classify mild and severe patients at an early stage.

Obesity is defined as abnormal fat accumulation and is a common, costly condition (7). According to the WHO report, obesity is classified into three groups based on body mass index (BMI). The prevalence of obesity has tripled since 1975 and is an established risk factor of other diseases such as diabetes, hypertension, heart disease, and cancers (8-10). Paradoxically, obesity has been shown to decrease mortality among patients diagnosed with pneumonia and ARDS (1114). Recent epidemiological studies have shown obesity to be associated with both neutral and increased risk of mortality among patients diagnosed with COVID-19 (15, 16), but mechanisms underlying this are still unclear. Previous studies noted that the number of hospitalization and mechanical ventilation cases is higher in patients with obesity that can be associated with an increased rate of mortality $(17,18)$. Moreover, obesity is related to the downregulation of the inflammatory pathway, which leads to increase expression of inflammatory molecules, including interleukin-6 (IL-6). Age and elevated IL-6 were proclaimed as significant predictors of in-hospital mortality $(19,20)$.

\section{Goal of Investigation}

The objectives of the current comprehensive and rigorous metaanalysis were to investigate relevant epidemiological studies for evaluating the association between obesity and mortality of COVID-19 patients. The findings of this study could help healthcare providers to take preventive actions and use early treatment strategies for these high-risk groups.

\section{Research Aims}

- To determine whether obesity is associated with an increased rate of mortality among the patients diagnosed with COVID-19. - To calculate the strength of association between class I, class II, and class III obesity and mortality of COVID-19 patients.
- To elucidate the association between associated factors (e.g., diabetes, CKD, COPD, smoking) and mortality of COVID19 patients.

\section{METHODS}

\section{Meta-Analysis Guidelines}

The Preferred Reporting Items for Systematic Reviews and Meta-Analyses (PRISMA) was used to select potential study inclusion. Moreover, the Meta-analysis of Observational Studies in Epidemiology (MOOSE) guidelines were also considered for this study (21) (Supplementary Table 1).

\section{Search Strategy}

We did a compressive systematic search to collect all relevant articles that evaluated the effect of COVID-19 on patients in terms of obesity and mortality. Any article published in English was considered for inclusion; an article search strategy was developed to retrieve all articles between January 1 and August 30, 2020. Articles search were conducted in the most popular electronic databases such as Scopus, PubMed, EMBASE, and Web of Science. The following search terms were used to retrieve articles: "Obesity" OR "BMI," OR "Overweight" AND "mortality related to COVID-19" OR "death related to COVID19" (Supplementary Table 2). We removed all duplicate articles, and a final search for relevant articles was performed on the reference list of retrieved articles.

\section{Selection Criteria}

We developed a priori inclusion criteria and included articles of COVID-19 patients' mortality due to obesity, associated risk factors such as demographic factors, and comorbidities. Articles were included if they (a) were peer-reviewed, (b) were published in English, (c) were cohort or comparison design, (d) included patients with more than 20, (e) and reported effect size as odds ratio (OR), risk ratio (RR) or hazard ratio (HR). We excluded studies if they were published as a review or case series.

\section{Study Selection}

Two authors (MdI and TP) screened titles and abstracts from the search results. Predefined selection criteria were used to select relevant full-text articles during the screening process. Afterward, all full-text articles were evaluated carefully for inclusion and data extraction. The same two authors (MdI and TP), however, independently evaluated each potential article for inclusion. Any disagreement during those screening process was resolved by the main investigator (Y-CL).

\section{Data Extraction}

All the selected studies were then finally reviewed to extract potential information regarding obesity and mortality of patients with COVID-19 and associated risk factors. One author collected information about author name, publication years, study design, number of patients with COVID-19, number of alive patients and number of dead patients, percentage of mortality, risk factors, inclusion and exclusion criteria, and effect sizes. 


\section{Quality Assessment}

The Quality In Prognosis Studies (QUIPS) tool was utilized to examine the risk of bias ( $\mathrm{RoB})$, which is recommended by the Cochrane Prognosis Methods group (22). The QUIPS tool has six evaluation domains that are used to evaluate validity and bias in studies of prognostic factors: (a) study participation, (b) study attrition, (c) prognostic factor measurement, (d) outcome measurement, (e) study confounding, and (f) statistical analysis and reporting (23). RoB is classified into three groups: low, moderate, and high risk. The Grading of Recommendations Assessment, Development and Evaluation (GRADE) approach was considered to assess the confidence in the estimate of effect. GRADE was utilized to determine the quality of evidence based on several factors such as risk of bias, inconsistency, imprecision, indirectness, and publication bias.

\section{Statistical Analysis}

The primary outcome was the mortality of patients with COVID19 due to obesity, and secondary outcomes were increased risk of mortality among class I, class II, and class III obesity. In subgroup analyses, we also evaluated the risk of mortality associated with comorbidities, age, gender, and other factors. Risk ratios with 95\%CIs were calculated from the HRs or ORs. We used a random-effects model to calculate the heterogeneity between studies. However, studies heterogeneity was assessed using Cochran Q statistics and inconsistency statistics $\left(I^{2}\right)$. We followed previous studies that considered heterogeneity as very low, low, medium, and high if $\mathrm{I}^{2}$ value $0 \sim 25 \%, 25-50 \%, 50 \sim 75 \%$, and $>75 \%(24,25)$. The Forest plot was drawn to present effect size, and the funnel plot was drawn to present publication bias.

\section{RESULTS}

\section{Study Selection}

A total of 3,513 unique articles were retrieved after searching for electronic databases. Of those, 3,492 articles were excluded after reviewing their titles and abstracts because they have not fulfilled pre-specified selection criteria. Overall, 21 articles went to full-text review and were scrutinized for final inclusion. However, four studies were further excluded because they have been published in the form of a review. Finally, 17 articles met the inclusion criteria for meta-analysis $(15,16,26-40)$. Figure 1 shows the overall study selection process.

\section{Study Characteristics}

Table 1 shows the clinical characteristics of the included studies. Of those, 16 studies had a retrospective cohort study design, and one study had a prospective design. Eleven studies used data from North American patients, four studies used data from European countries (France, Italy, and the UK), and one study used data from 47 countries. The range of male patients was $43.3-80.2 \%$. All of the studies used demographics, clinical variables.

\section{Quality of Evidence}

The QUIPS tool was used to evaluate the risk bias among the included studies. Thirteen studies were of low risk bias, and four studies were of moderate risk bias (Figure 2). The overall quality of evidence is strong in the meta-analysis. Supplementary Table 3 presents a summary of the GRADE evidence profile for our meta-analysis. For the increased rate of mortality among obese patients, the certainty was "low."

\section{Primary Outcome}

\section{Obesity and Mortality of Patients With COVID-19}

Of the 17 studies considered in our meta-analysis, 16 studies reported a significantly increased risk of mortality among patients with COVID-19, and one study reported a decreased risk of mortality. All the studies adjusted their effect size with potential variables to reduce potential bias. Collectively, our meta-analysis suggested a significantly increased risk of mortality with obesity, with a pooled RR of 1.42 (95\%CI: $1.24-1.63, p<0.001$ ) (Figure 3). The $I^{2}$ statistics among the studies was $67.94 \%$, indicating a moderate risk of heterogeneity.

\section{Secondary Outcome}

\section{Types of Obesity and COVID-19 Mortality}

We also pooled RR to evaluate the risk of mortality based on three types of obesity such as class I, class II, and class III obesity. Class III obesity was strongly associated with an increased risk of mortality, with a pooled $\mathrm{RR}_{\text {adjust }}$ of 1.92 (95\%CI: $1.50-2.47, p$ $<0.001)$. There was insignificant low heterogeneity among the studies $\left(I^{2}=31.99, Q=5.88, \operatorname{tau}^{2}=0.02, p=0.20\right)$ (Figure 4A). Class I and class II obesity also showed a strong association with an increased risk of mortality, with a pooled $\mathrm{RR}_{\text {adjust }}$ of 1.27 (95\%CI: $1.05-1.54, p=0.01$ ), and 1.56 (95\%CI: $1.11-2.19$, $p<0.01$ ), respectively (Figures $4 \mathbf{B}, \mathbf{C}$ ). There was significant moderate heterogeneity among the studies for Class I $\left(I^{2}=60.00\right.$, $\left.Q=5, \operatorname{tau}^{2}=0.03, p=0.02\right)$ and higher heterogeneity among the studies were observed for class II $\left(I^{2}=80.34, Q=25.43\right.$, $\operatorname{tau}^{2}=$ $0.12, p<0.001)$.

\section{Subgroup Analysis}

Subgroup analyses are presented in Table 2 . The 7 studies reported the risk of mortality among patients with obesity who were more than 65 years old. The pooled $\mathrm{RR}_{\text {adjust }}$ was 2.54 (95\%CI: 1.62-3.97, $p<0.001$ ) and heterogeneity among the studies was $\left(I^{2}=89.33, Q=56.24\right.$, tau $^{2}=0.24, p<$ 0.001). Furthermore, six studies evaluated the risk of COVID-19 mortality among male patients and showed a significantly higher risk $\left(\mathrm{RR}_{\text {adjust }}: 1.38,95 \% \mathrm{CI}: 1.25-1.51, p<0.001\right)$. There was a lower risk of heterogeneity among the studies $\left(I^{2}=9.57, Q=\right.$ 5.53, $\left.\operatorname{tau}^{2}=0.001, p=0.35\right)$.

We also evaluated the risk of mortality among obese COVID-19 patients with various comorbidity such as diabetes, hypertension, CKD, COPD, and stroke. The pooled RR for COVID-19 mortality among patients with diabetes was 1.19 (95\%CI: $1.07-1.32, p=0.001)$. However, the pooled RR among the patients with stroke, CKD, COPD, and hypertension were 1.80 (95\%CI: 0.89-3.64, $p=0.10$ ), 1.57 (95\%CI: $1.57-1.91, p<$ 0.001 ), 1.34 (95\%CI: 1.18-1.52, $p<0.001$ ), and 1.07 (95\%CI: $0.92-1.25, p=0.35)$, respectively. 


\section{PRISMA 2009 Flow Diagram}

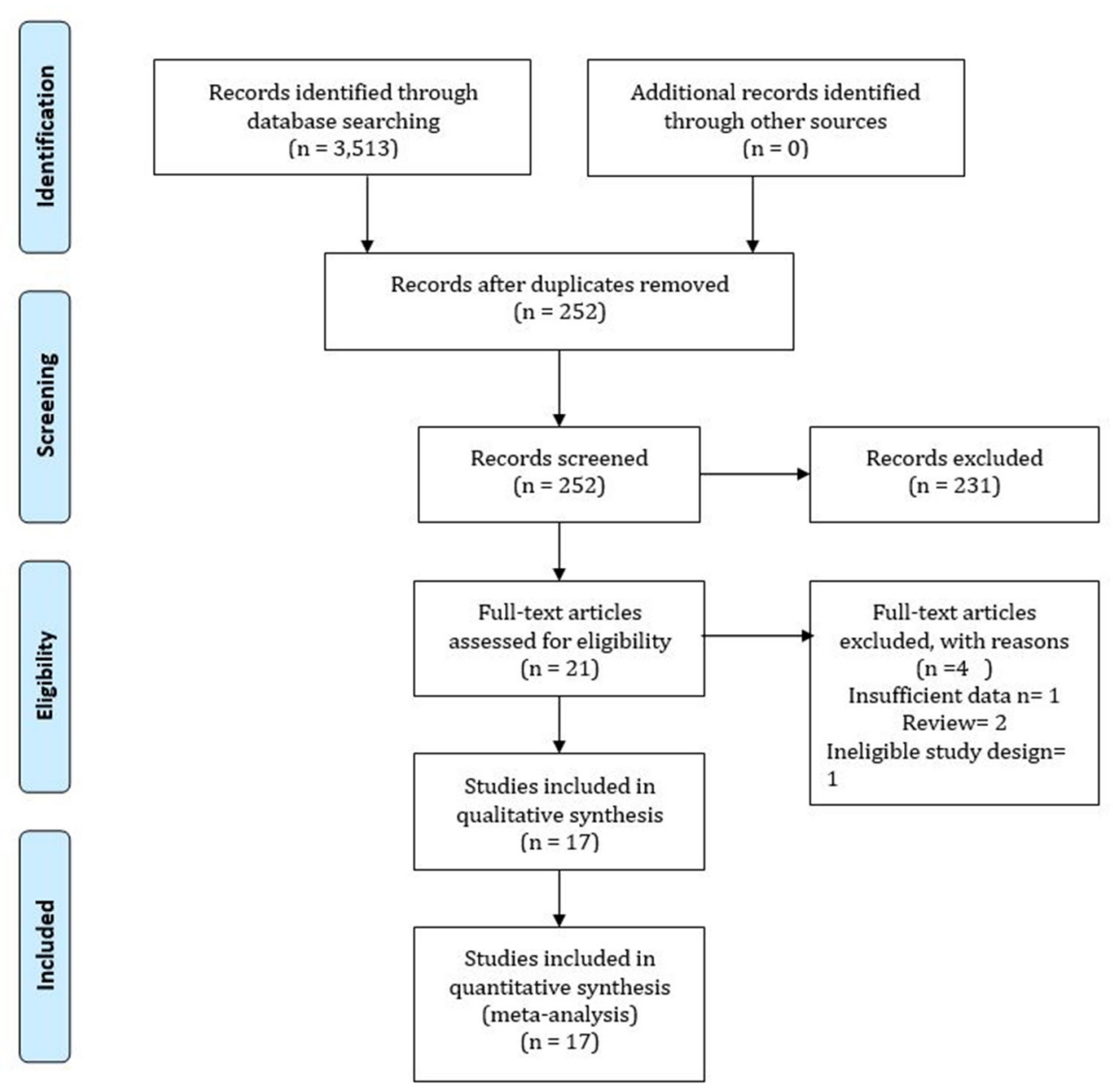

FIGURE 1 | Flow diagram of the study selection process.

\section{Risk of Bias}

Figure 5A depicts the funnel plot that indicates no publication bias among the studies. Egger's regression test was used to evaluate the funnel asymmetry, which showed no publication bias $(p<0.05)$. Moreover, Figure 5B shows the funnel plot with missing studies imputed by the trim and fill method. There was no missing study to be filled in the plot, and the overall log risk ratio became 1.42 95\%CI (1.24-1.63).

\section{DISCUSSION}

\section{Main Findings}

This rigorous meta-analysis of 17 studies showed that obesity is associated with an increased risk of mortality among patients with COVID-19, especially patients aged more than 65 years. Furthermore, class III obesity patients observed a greater risk of mortality compared to class I and class II obesity. The risk of mortality was varied in COVID-19 patients with various comorbidities. Our findings may help to categorized patients at different risk groups and to make potential early prevention and treatment strategies possible.

\section{Comparison With Previous Studies}

Our study findings are similar to those of two previous studies $(41,42)$. Hussain et al. (41) included 14 studies, but only 6 studies were used to assess the relationship between obesity and mortality in COVID-19. This study lacks statistical power in subgroup analyses and included no consideration of different types of obesity and risk of mortality of patients with COVID19. Another study showed a positive relation, though lack of evidence because they included preprints (non-peer-reviewed articles), and there were no subgroup analyses (42). 


\begin{tabular}{|l|l|l|l|l|l|l|l|}
\hline Study & $\begin{array}{l}\text { Study } \\
\text { participants }\end{array}$ & $\begin{array}{l}\text { Study } \\
\text { attrition }\end{array}$ & $\begin{array}{l}\text { Prognostic } \\
\text { factor } \\
\text { measurement }\end{array}$ & $\begin{array}{l}\text { Outcome } \\
\text { measurement }\end{array}$ & $\begin{array}{l}\text { Study } \\
\text { confounding }\end{array}$ & $\begin{array}{l}\text { Statistical } \\
\text { analysis and } \\
\text { reporting }\end{array}$ & $\begin{array}{l}\text { Overall } \\
\text { risk bias }\end{array}$ \\
\hline Bello-Chavolla 2020 & & & & & & \\
\hline Klang 2020 & & & & & & & \\
\hline Nakeshbandi 2020 & & & & & & & \\
\hline N. Pettit 2020 & & & & & & & \\
\hline Palaiodimos 2020 & & & & & & & \\
\hline Czernichow 2020 & & & & & & & \\
\hline Hamer 2020 & & & & & & & \\
\hline Rottoli 2020 & & & & & & & \\
\hline Zhang 2020 & & & & & & & \\
\hline Tartof 2020 & & & & & & & \\
\hline Price-Haywood 2020 & & & & & & & \\
\hline Goyal 2020 & & & & & & & \\
\hline Halasz 2020 & & & & & & & \\
\hline Wang 2020 & & & & & & \\
\hline Hajifathalian 2020 & & & & & & \\
\hline Kim 2020 & & & & & & \\
\hline Anderson 2020 & & & & & & \\
\hline
\end{tabular}

\begin{tabular}{|l|l|}
\hline & Low risk \\
\hline & Moderate risk \\
\hline & High risk \\
\hline
\end{tabular}

FIGURE 2 | Risk of bias according to the QUIPS tool.

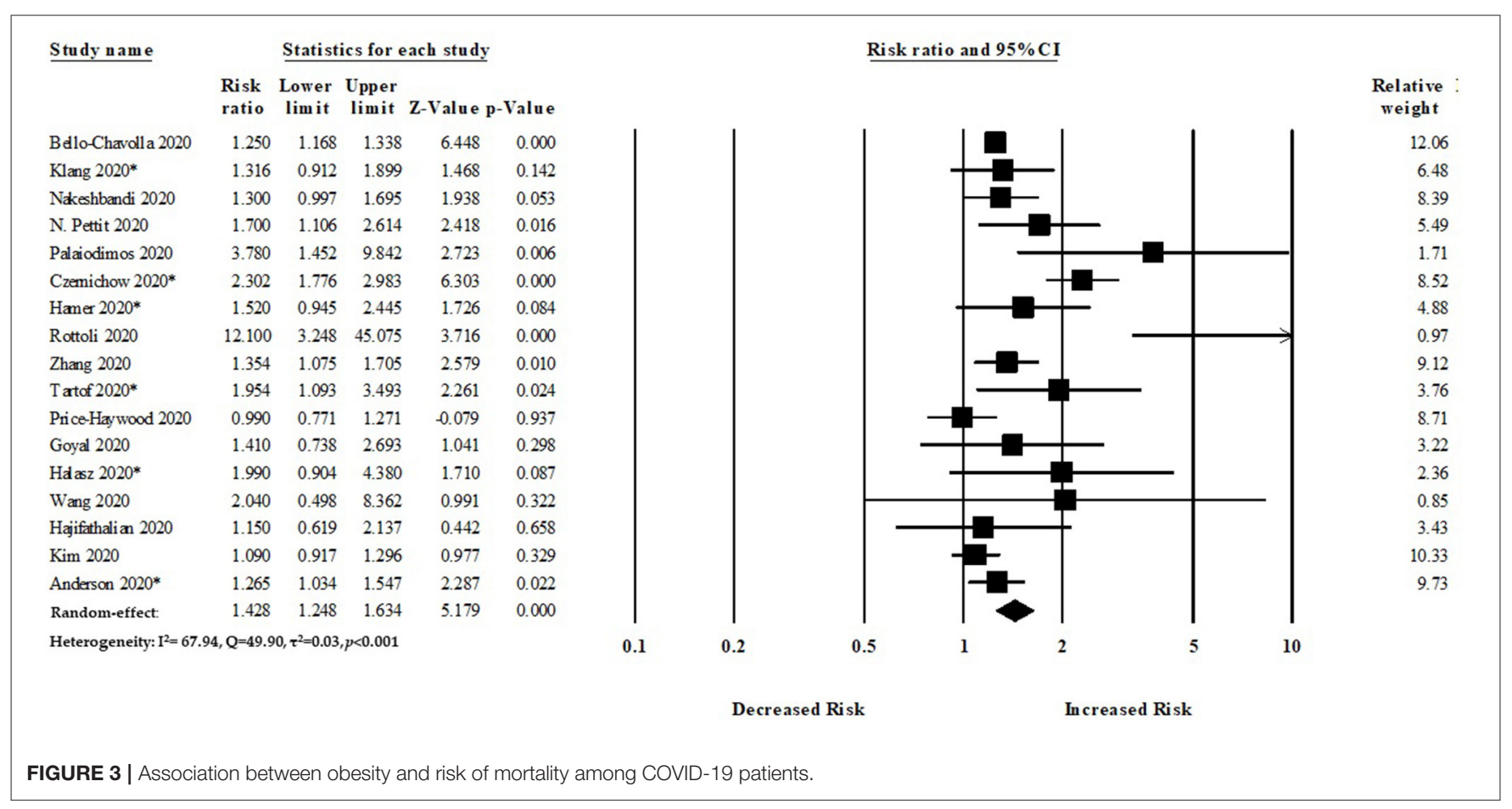


TABLE 1 | Characteristics of the included studies assessing the risk of mortality of COVID-19 patients with obesity.

\begin{tabular}{|c|c|c|c|c|c|c|c|}
\hline Author & Country & Design & $\begin{array}{l}\text { Total } \\
\text { sample }\end{array}$ & $\begin{array}{c}\text { Male } \\
(\%)\end{array}$ & $\begin{array}{c}\text { Age } \\
\text { (mean/median) }\end{array}$ & Variable & Findings \\
\hline Bello-Chavolla et al. (33) & Mexico & Retrospective & 177,133 & 57.70 & 63.5 & $\begin{array}{l}\text { Demographics, clinical, } \\
\text { smoking }\end{array}$ & $1.25(1.17-1.34)$ \\
\hline Klang et al. (35) & USA & Retrospective & 3,406 & 56 & 76 & $\begin{array}{l}\text { Demographics, clinical, } \\
\text { smoking }\end{array}$ & $1.31(0.91-1.89)$ \\
\hline Nakeshbandi et al. (36) & USA & Retrospective & 504 & 52 & 68 & $\begin{array}{l}\text { Demographics, clinical, } \\
\text { smoking }\end{array}$ & $1.30(0.99-1.93)$ \\
\hline Palaiodimos et al. (29) & USA & Retrospective & 200 & 49 & 64 & $\begin{array}{l}\text { Demographics, clinical, } \\
\text { smoking, symptoms }\end{array}$ & $3.78(1.45-9.84)$ \\
\hline Czernichow et al. (34) & France & Prospective & 5,795 & 65.41 & 59.6 & Demographics, and clinical & $2.30(1.77-2.98)$ \\
\hline Hamer et al. (15) & UK & Retrospective & 334,329 & 45.5 & 56.4 & $\begin{array}{l}\text { Demographics, biomarker, } \\
\text { smoking }\end{array}$ & $1.52(0.94-2.44)$ \\
\hline Price-Haywood et al. (16) & USA & Retrospective & 3,481 & 43.3 & 55.5 & $\begin{array}{l}\text { Demographics, clinical, } \\
\text { locations }\end{array}$ & $0.99(0.77-1.27)$ \\
\hline Goyal et al. (39) & USA & Retrospective & 1,687 & 60 & 66.5 & $\begin{array}{l}\text { Demographics, clinical, } \\
\text { laboratory, smoking, } \\
\text { in-hospital events }\end{array}$ & $1.41(0.73-2.69)$ \\
\hline Halasz et al. (27) & Italy & Retrospective & 242 & 80.2 & 64 & $\begin{array}{l}\text { Demographics, clinical, } \\
\text { laboratory }\end{array}$ & $1.99(0.90-4.38)$ \\
\hline Wang et al. (30) & USA & Retrospective & 58 & 52 & 67 & $\begin{array}{l}\text { Demographics, laboratory, } \\
\text { clinical }\end{array}$ & $2.04(0.49-8.36)$ \\
\hline Hajifathalian et al. (28) & USA & Retrospective & 770 & 61 & 63.5 & $\begin{array}{l}\text { Demographics, clinical, } \\
\text { laboratory data, clinical } \\
\text { outcomes }\end{array}$ & $1.15(0.61-2.13)$ \\
\hline
\end{tabular}

\section{Biological Plausibility}

Several biological mechanisms have been reported to explain the association between obesity and increase the risk of mortality. First, it is reported that both ectopic fat and COVID-19 are responsible for upregulation of proinflammatory, angiotensin II (ATII), and prothrombotics. Patients with obesity observe a decreased level of inflammatory adipokines, adiponectin, which is liked to an increased rate of ATII $(43,44)$. Similarly, coronavirus reduces the activity of ACE2 inhibitor, which leads to increase ATII level $(45,46)$. Higher levels of ATII might contribute to the progression of lung injury among patients diagnosed with COVID-19 by triggering NADH/NADPH oxidase system (47) and promoting contraction and vasoconstriction (48). Furthermore, an increased expression of inflammatory molecules enhances the production of cytokines [e.g., tumor necrosis factor alpha (TNF- $\alpha$ ) and IL-6] (49), which are associate with alveolar damage and an increased rate of mortality (50).

\section{Public Health Implication}

COVID-19 pandemic has created serious concern globally, and people are eagerly waiting for potential vaccines. There is no exact and effective treatment for this virus so far, and global morbidity and mortality thus increase day by day (51). COVID19 shows a wide spectrum of symptoms; some patients recovered without complications. However, some patients affected by serious illness have needed to transfer to the ICU, require a prolonged hospital stay, and may even die (52). Elderly patients were more vulnerable in this disease because they have multiple diseases. A significant number of studies reported that elderly patients and patients with diabetes, stroke, CKD, and COPD are associated with bad outcomes $(53,54)$. Obesity, especially class 3 obesity, was associated with an increased rate of mortality among patients diagnosed with COVID-19. It is, however, not surprising because patients with obesity who had the H1N1 influenza virus also observed prolong hospitalization, mechanical ventilation, and death when it was calculated as an independent risk factor $(55,56)$. 


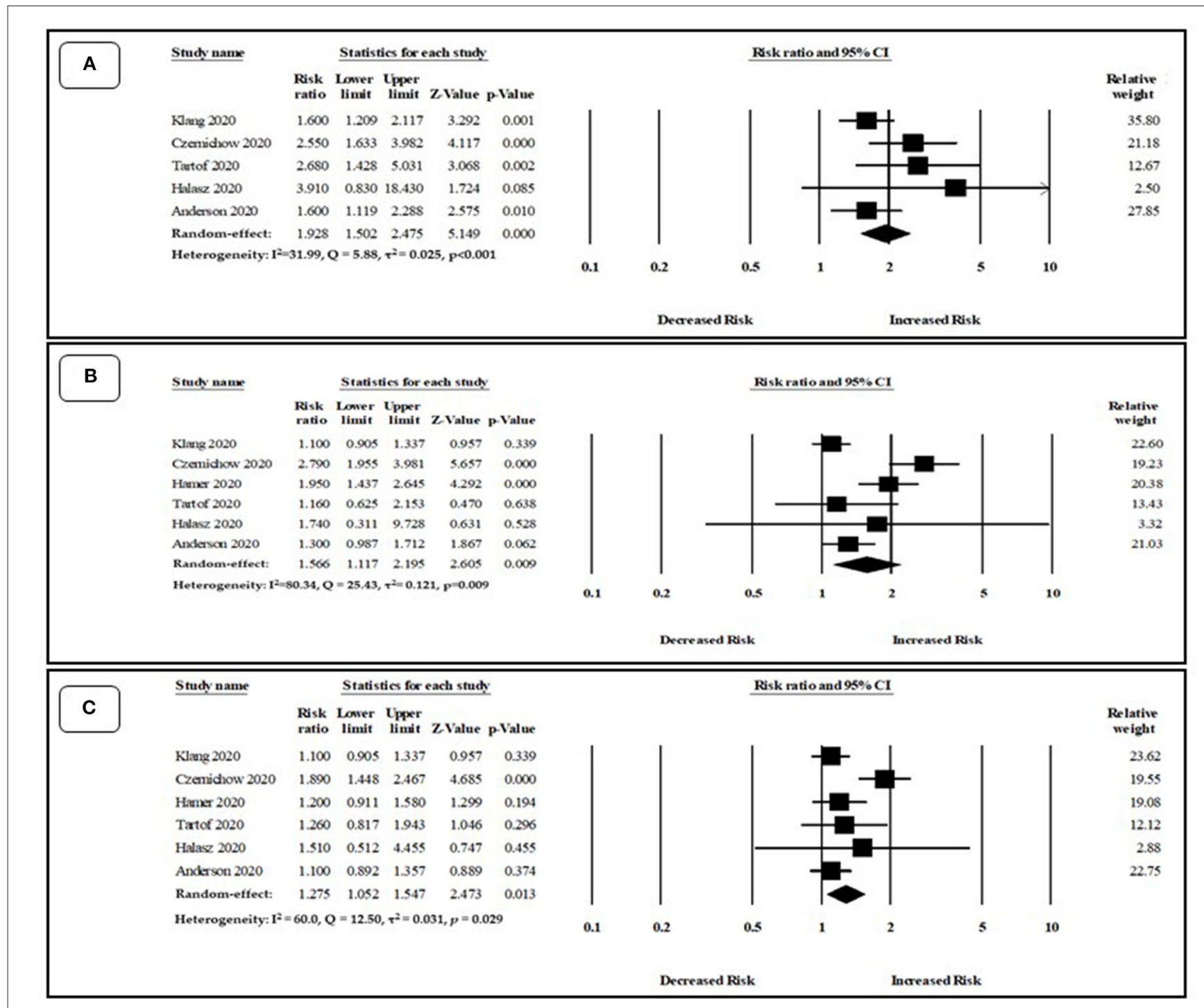

FIGURE 4 | Association between (A) Class III, (B) class II, (C) class I obesity and risk of mortality among COVID-19 patients.

TABLE 2 | Subgroup analyses.

\begin{tabular}{|c|c|c|c|c|c|c|}
\hline & \multicolumn{3}{|c|}{ Pooled estimate } & \multicolumn{3}{|c|}{ Test of heterogeneity } \\
\hline & $N$ & RR with $95 \%$ Cl & $p$-Value & $\tau^{2}$ & $I^{2}$ & $p$-Value \\
\hline \multicolumn{7}{|l|}{ Demographic } \\
\hline Male & 6 & $1.38(1.25-1.51)$ & $<0.001$ & 0.001 & 9.57 & 0.35 \\
\hline$\geq 65$ years & 7 & $2.54(1.62-3.97)$ & $<0.001$ & 0.24 & 89.33 & $<0.001$ \\
\hline \multicolumn{7}{|l|}{ Comorbidity } \\
\hline Diabetes & 11 & $1.19(1.07-1.32)$ & 0.001 & 0.012 & 54.15 & 0.016 \\
\hline Hypertension & 9 & $1.07(0.92-1.25)$ & 0.351 & 0.029 & 60.58 & 0.009 \\
\hline CKD & 7 & $1.57(1.29-1.91)$ & $<0.001$ & 0.036 & 69.18 & 0.003 \\
\hline CPOD & 5 & $1.34(1.18-1.52)$ & $<0.001$ & 0.004 & 16.12 & 0.312 \\
\hline Stroke & 2 & $1.80(0.89-3.64)$ & 0.100 & 0 & 0 & 0.37 \\
\hline \multicolumn{7}{|l|}{ Others } \\
\hline Smoking & 6 & $1.13(0.91-1.40)$ & 0.242 & 0.027 & 46.57 & 0.09 \\
\hline
\end{tabular}

Several population-based cohort studies reported that obesity is linked to increased comorbidity like diabetes, hypertension, and heart disease. However, the mortality rate among patients with obesity proportionally increased with $\operatorname{BMI}(57,58)$. Moreover, obesity makes patients' conditions worse if patients develop infections by downregulating the inflammatory cascade. Hyperactivation of inflammatory pathways surge the level of cytokines, adiponectin, and leptin and distort both macro- and micro-vascular responses (59). Obesity is also associated with lung function impairment, which involves altering mechanics and airway resistance and decreasing gas exchange $(60,61)$. The findings of our study suggest that physicians should focus more on COVID-19 patients with obesity because this group of patients is at high risk of worse consequences. Moreover, our results highlight the need for vigilance, priority on testing, and an earlier start to treatment in obese patients with COVID-19. Previous studies also mentioned that obesity increased the rate of hospitalization, worsened patient conditions, and increased 


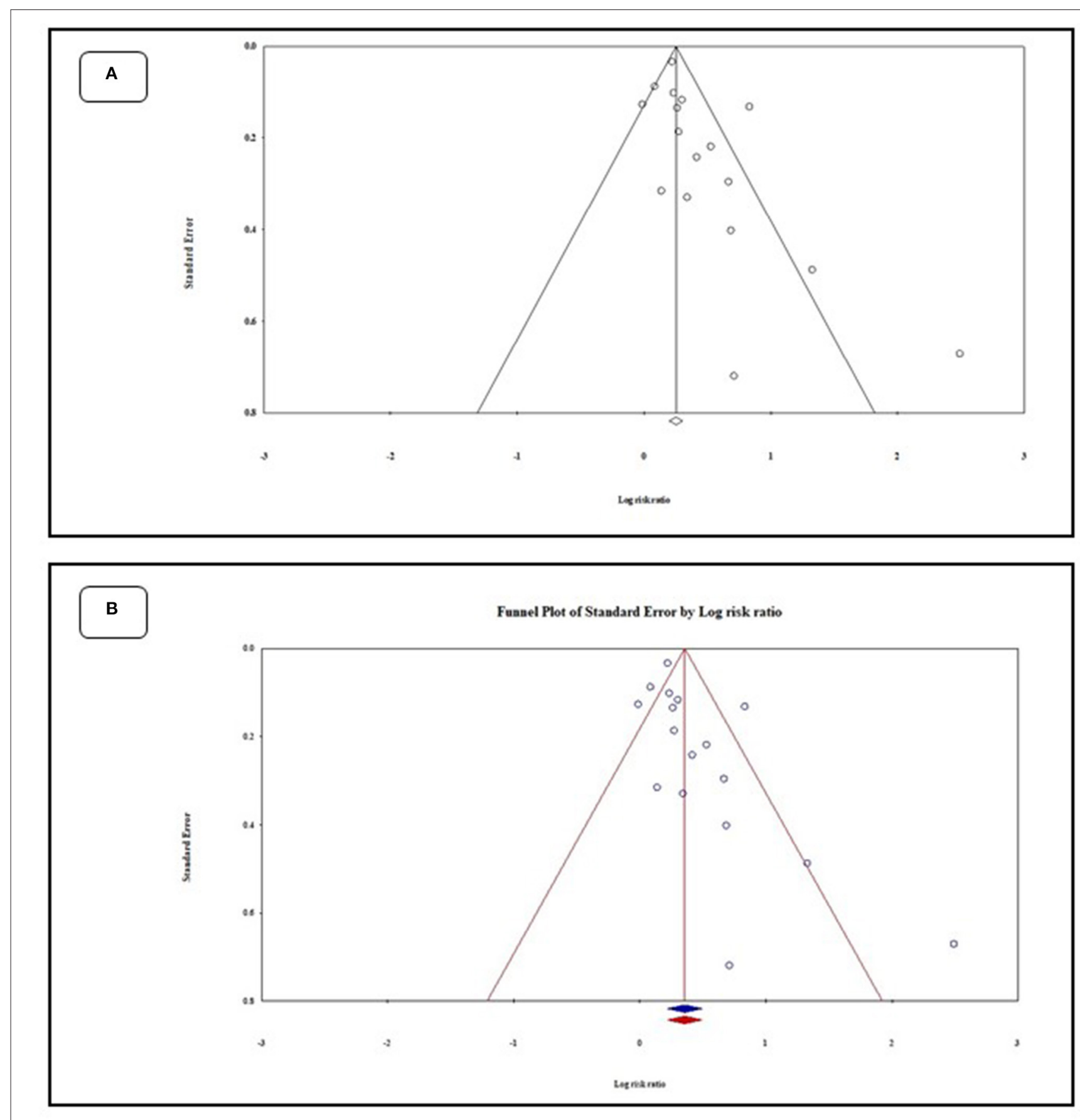

FIGURE 5 | Funnel plots of meta-analysis before (A) and after (B) applying the fill and trim method.

invasive mechanical ventilation in those diagnosed with COVID$19(15,62)$.

\section{Strengths and Limitations}

Our study has several strengths. First, this is the first comprehensive and rigorous meta-analysis that assessed the association between obesity and the risk of mortality among patients with COVID-19. This meta-analysis included 17 studies, and only peer-reviewed articles were included for calculating the magnitude of risk because preprint articles have lots of room for improvement. Second, the risk of bias is low, and heterogeneity among the study is moderate. However, several factors showed higher heterogeneity among the studies. Third, this meta-analysis also evaluated associated factors that can contribute to a high risk of mortality. Finally, only adjusted effect size was considered to calculate pooled RR, which indicates strong evidence with a low 
risk of bias. Our study has several limitations that need to be addressed. First, we could not compare risk among patients aged $<65$ due to data constraints. Second, pneumonia is a high-risk factor for mortality among COVID-19 patients because only one study reported about this issue. This study showed the association between COPD and the risk of mortality among patients with COVID-19. Third, our study did not show the difference in the rate of mortality among various races and locations; this could have added value to the present evidence.

\section{CONCLUSION}

We conducted a comprehensive systematic review and rigorous meta-analysis of studies reporting the risk of mortality among COVID-19 patients with obesity. Our study findings showed that obesity is associated with an increased risk of mortality among patients with COVID-19. Importantly, the risk of mortality was higher among class III obesity than class I and II obesity. Physicians should be aware of these risk factors and make a quick decision for intervention. Future studies are urgently needed to clarify the pathophysiological relationship between obesity and the risk of mortality among COVID-19 patients.

\section{DATA AVAILABILITY STATEMENT}

The original contributions presented in the study are included in the article/Supplementary Material, further inquiries can be directed to the corresponding author/s.

\section{REFERENCES}

1. Chen N, Zhou M, Dong X, Qu J, Gong F, Han Y, et al. Epidemiological and clinical characteristics of 99 cases of 2019 novel coronavirus pneumonia in Wuhan, China: a descriptive study. Lancet. (2020) 395:507-13. doi: 10.1016/S0140-6736(20)30211-7

2. Ornell F, Schuch JB, Sordi AO, Kessler FHP. "Pandemic fear" and COVID19: mental health burden and strategies. Braz J Psychiatry. (2020) 42:232-5. doi: 10.1590/1516-4446-2020-0008

3. McKibbin, Warwick J., Fernando, Roshen, The global macroeconomic impacts of COVID-19: seven scenarios (March 2, 2020). CAMA Working Paper No. 19/2020. doi: 10.2139/ssrn.3547729 Available online at: https://ssrn. com/abstract $\$=\$ 3547729$

4. Siddiqi HK, Mehra MR. COVID-19 illness in native and immunosuppressed states: a clinical-therapeutic staging proposal. J Heart Lung Transplant. (2020) 39:405. doi: 10.1016/j.healun.2020.03.012

5. Wang D, Hu B, Hu C, Zhu F, Liu X, Zhang J, et al. Clinical characteristics of 138 hospitalized patients with 2019 novel coronavirus-infected pneumonia in Wuhan, China. JAMA. (2020) 323:1061-9. doi: 10.1001/jama.20 20.1585

6. Yang W, Cao Q, Qin L, Wang X, Cheng Z, Pan A, et al. Clinical characteristics and imaging manifestations of the 2019 novel coronavirus disease (COVID19): a multi-center study in Wenzhou city, Zhejiang, China. J Infect. (2020) 80:388-93. doi: 10.1016/j.jinf.2020.02.016

7. Skinner AC, Skelton JA. Prevalence and trends in obesity and severe obesity among children in the United States, 1999-2012. JAMA Pediatr. (2014) 168:561-6. doi: 10.1001/jamapediatrics.2014.21

8. Stengel B, Tarver-Carr ME, Powe NR, Eberhardt MS, Brancati FL. Lifestyle factors, obesity and the risk of chronic kidney disease. Epidemiology. (2003) 14:479-87. doi: 10.1097/01.EDE.0000071413. 55296.c4

\section{AUTHOR CONTRIBUTIONS}

TP and MI: conceptualization. TP and HY: methodology. MI: Software, resources, data curation and writing - original draft preparation. ML, W-SJ, and Y-CL: validation. TP: formal analysis and visualization. $\mathrm{M}-\mathrm{HH}$ : investigation. Y-CL: writing - review and editing and supervision. All authors contributed to the article and approved the submitted version.

\section{FUNDING}

This research was funded in part by the Ministry of Education (MOE) under grants MOE 109-6604-001-400 and DP2-109-21121-01-A-01 and the Ministry of Science and Technology (MOST) under grant MOST 109-282 3-8-038-004.

\section{ACKNOWLEDGMENTS}

We would like to thanks our colleague who is a Native English Speaker for editing this manuscript.

\section{SUPPLEMENTARY MATERIAL}

The Supplementary Material for this article can be found online at: https://www.frontiersin.org/articles/10.3389/fmed. 2021.620044/full\#supplementary-material

9. Ejerblad E, Fored CM, Lindblad P, Fryzek J, McLaughlin JK, Nyrén O. Obesity and risk for chronic renal failure. J Am Soc Nephrol. (2006) 17:1695-702. doi: 10.1681/ASN.2005060638

10. Hales CM, Carroll MD, Fryar CD, Ogden CL. Prevalence of Obesity and Severe Obesity Among Adults: United States, 2017-2018. NCHS Data Brief, no 360. Hyattsville, MD: National Center for Health Statistics (2020).

11. Zhi G, Xin W, Ying W, Guohong X, Shuying L. "Obesity paradox" in acute respiratory distress syndrome: asystematic review and meta-analysis. PLoS ONE. (2016) 11:e0163677. doi: 10.1371/journal.pone.0163677

12. King P, Mortensen EM, Bollinger M, Restrepo MI, Copeland LA, Pugh MJV, et al. Impact of obesity on outcomes for patients hospitalised with pneumonia. Eur Respir J. (2013) 41:929-34. doi: 10.1183/09031936.00185211

13. Nie W, Zhang Y, Jee SH, Jung KJ, Li B, Xiu Q. Obesity survival paradox in pneumonia: a meta-analysis. BMC Med. (2014) 12:61. doi: 10.1186/1741-7015-12-61

14. Corrales-Medina VF, Valayam J, Serpa JA, Rueda AM, Musher DM. The obesity paradox in community-acquired bacterial pneumonia. Int J Infect Dis. (2011) 15:e54-7. doi: 10.1016/j.ijid.2010.09.011

15. Hamer M, Gale CR, Kivimäki M, Batty GD. Overweight, obesity, and risk of hospitalization for COVID-19: a community-based cohort study of adults in the United Kingdom. Proc Natl Acad Sci. (2020) 117:21011-3. doi: $10.1073 /$ pnas.2011086117

16. Price-Haywood EG, Burton J, Fort D, Seoane L. Hospitalization and mortality among black patients and white patients with COVID-19. N Engl J Med. (2020) 382:2534-43. doi: 10.1056/NEJMsa2011686

17. Petrilli CM, Jones SA, Yang J, Rajagopalan H, O'Donnell L, Chernyak Y, et al. Factors associated with hospital admission and critical illness among 5279 people with coronavirus disease 2019 in New York City: prospective cohort study. BMJ. (2020) 369:m1966. doi: 10.1136/bmj.m1966

18. Lighter J, Phillips M, Hochman S, Sterling S, Johnson D, Francois F, et al. Obesity in patients younger than 60 years is a risk factor for 
COVID-19 hospital admission. Clinical Infectious Diseases. (2020) 71:896-7. doi: $10.1093 / \mathrm{cid} /$ ciaa415

19. Maeda T, Obata R, Dahlia Rizk DO, Kuno TJ. The association of interleukin6 value, interleukin inhibitors, and outcomes of patients with COVID-19 in New York City. J Med Virol. (2020) 96:463-71. doi: 10.1002/jmv.26365

20. Aziz M, Fatima R, Assaly RJ. Elevated interleukin-6 and severe COVID-19: a meta-analysis. J Med Virol. (2020) 92:2283-5. doi: 10.1002/jmv.25948

21. Moher D, Liberati A, Tetzlaff J, Altman DG, med PGJP. Preferred reporting items for systematic reviews and meta-analyses: the PRISMA statement. Int $J$ Surg. (2010) 8:336-41. doi: 10.1016/j.ijsu.2010.02.007

22. Hayden JA, van der Windt DA, Cartwright JL, Côté P, Bombardier C. Assessing bias in studies of prognostic factors. Ann Intern Med. (2013) 158:280-6. doi: 10.7326/0003-4819-158-4-201302190-00009

23. Hemingway H, Riley RD, Altman DG. Ten steps towards improving prognosis research. BMJ. (2009) 339:b4184. doi: 10.1136/bmj.b4184

24. Islam MM, Iqbal U, Walther B, Atique S, Dubey NK, Nguyen P-A, et al. Benzodiazepine use and risk of dementia in the elderly population: a systematic review and meta-analysis. Neuroepidemiology. (2016) 47:181-91. doi: $10.1159 / 000454881$

25. Poly T, Islam M, Yang H-C, Wu C. Proton pump inhibitors and risk of hip fracture: a meta-analysis of observational studies. Osteoporosis International. (2019) 30:103-14. doi: 10.1007/s00198-018-4788-y

26. Kim L, Garg S, O'Halloran A, Whitaker M, Pham H, Anderson EJ, et al. Interim analysis of risk factors for severe outcomes among a cohort of hospitalized adults identified through the Us coronavirus disease 2019 (COVID-19)-associated hospitalization surveillance network (COVID-NET). medRxiv. (2020) 28:1606-12.

27. Halasz G, Leoni ML, Villani GQ, Nolli M, Villani M. Obesity, overweight and survival in critically ill patients with SARS-CoV-2 pneumonia: is there an obesity paradox? Preliminary results from Italy. Euro J Prev. Cardiol. (2020). doi: $10.1177 / 2047487320939675$

28. Hajifathalian K, Kumar S, Newberry C, Shah S, Fortune B, Krisko $\mathrm{T}$, et al. Obesity is associated with worse outcomes in COVID-19: analysis of Early Data From New York City. Obesity. (2020) 28:1606-12. doi: 10.1002/oby.22923

29. Palaiodimos L, Kokkinidis DG, Li W, Karamanis D, Ognibene J, Arora S, et al. Severe obesity, increasing age and male sex are independently associated with worse in-hospital outcomes, and higher in-hospital mortality, in a cohort of patients with COVID-19 in the Bronx, New York. Metabolism. (2020) 108:154262. doi: 10.1016/j.metabol.2020.154262

30. Wang B, Van Oekelen O, Mouhieddine T, Del Valle DM, Richter J, Cho HJ, et al. A tertiary center experience of multiple myeloma patients with COVID19: lessons learned and the path forward. J Hematol Oncol. (2020) 13:94. doi: 10.1186/s13045-020-00934-x

31. Tartof SY, Qian L, Hong V, Wei R, Nadjafi RF, Fischer H, et al. Obesity and mortality among patients diagnosed with COVID-19: results from an integrated health care organization. Annals Intern Med. (2020) 173:773-81. doi: 10.7326/M20-3742

32. Anderson MR, Geleris J, Anderson DR, Zucker J, Nobel YR, Freedberg D, et al. Body mass index and risk for intubation or death in SARS-CoV-2 Infection: a retrospective cohort study. Ann Intern Med. (2020) 173:782-90. doi: 10.7326/M20-3214

33. Bello-Chavolla OY, Bahena-Lopez JP, Antonio-Villa NE, Vargas-Vázquez A, González-Díaz A, Márquez-Salinas A, et al. Predicting mortality due to SARS-CoV-2: a mechanistic score relating obesity and diabetes to COVID19 outcomes in Mexico. J Clin Endocrinol Metab. (2020) 105:dgaa346 doi: 10.1210/clinem/dgaa346

34. Czernichow S, Beeker N, Rives-Lange C, Guerot E, Diehl JL, Katsahian S, et al. Obesity doubles mortality in patients hospitalized for SARS-CoV-2 in Paris hospitals, France: a cohort study on 5795 patients. Obesity (Silver Spring). (2020) 12:2282-89. doi: 10.1002/oby.23014

35. Klang E, Kassim G, Soffer S, Freeman R, Levin MA, Reich DL. Morbid obesity as an independent risk factor for COVID-19 mortality in hospitalized patients younger than 50. Obesity. (2020) 28:1595-9. doi: 10.1002/oby.22913

36. Nakeshbandi M, Maini R, Daniel P, Rosengarten S, Parmar P, Wilson C, et al. The impact of obesity on COVID-19 complications: a retrospective cohort study. Int J Obesy. (2020) 44:1832-7. doi: 10.1038/s41366-0200648-x
37. Pettit NN, MacKenzie EL, Ridgway J, Pursell K, Ash D, Patel B, et al. Obesity is associated with increased risk for mortality among hospitalized patients with COVID-19. Obesity. (2020) 28:1806-10. doi: 10.1002/oby.22941

38. Rottoli M, Bernante P, Belvedere A, Balsamo F, Garelli S, Giannella M, et al. How important is obesity as a risk factor for respiratory failure, intensive care admission and death in hospitalised COVID-19 patients? Results from a single Italian Centre. Eur J Endocrinol. (2020) 183:389-97. doi: 10.1530/EJE-20-0541

39. Goyal P, Ringel JB, Rajan M, Choi JJ, Pinheiro LC, Li HA, et al. Obesity and COVID-19 in New York City: a retrospective cohort study. Ann Intern Med. (2020) 173:855-8. doi: 10.7326/M20-2730

40. Zhang F, Xiong Y, Wei Y, Hu Y, Wang F, Li G, et al. Obesity predisposes to the risk of higher mortality in young COVID-19 patients. J Med Virol. (2020) 92:2536-42. doi: 10.1002/jmv.26039

41. Hussain A, Mahawar K, Xia Z, Yang W, Shamsi E-H. Obesity and mortality of COVID-19. Meta-analysis. Obes Res Clin Pract. (2020) 14:295-300. doi: 10.1016/j.orcp.2020.07.002

42. Popkin BM, Du S, Green WD, Beck MA, Algaith T, Herbst CH, et al. Individuals with obesity and COVID-19: a global perspective on the epidemiology and biological relationships. Obes Rev. (2020) 21:e13128. doi: $10.1111 /$ obr.13128

43. Fujita K, Maeda N, Sonoda M, Ohashi K, Hibuse T, Nishizawa H, et al. Adiponectin protects against angiotensin II-induced cardiac fibrosis through activation of PPAR- $\alpha$. Arterioscler Thromb Vasc Biol. (2008) 28:863-70. doi: 10.1161/ATVBAHA.107.156687

44. Ran J, Hirano T, Fukui T, Saito K, Kageyama H, Okada K, et al. Angiotensin II infusion decreases plasma adiponectin level via its type 1 receptor in rats: an implication for hypertension-related insulin resistance. Metabolism. (2006) 55:478-88. doi: 10.1016/j.metabol.2005.10.009

45. Cheng H, Wang Y, Wang GQJ. Organ-protective effect of angiotensinconverting enzyme 2 and its effect on the prognosis of COVID-19. J Med Virol. (2020) 92:726-30. doi: 10.1002/jmv.25785

46. Gheblawi M, Wang K, Viveiros A, Nguyen Q, Zhong J-C, Turner AJ, et al. Angiotensin-converting enzyme 2: SARS-CoV-2 receptor and regulator of the renin-angiotensin system: celebrating the 20th anniversary of the discovery of ACE2. Circ Res. (2020) 126:1456-74. doi: 10.1161/CIRCRESAHA.120.317015

47. Zhang Y, Murugesan P, Huang K, Cai H. NADPH oxidases and oxidase crosstalk in cardiovascular diseases: novel therapeutic targets. Nat Rev Cardiol. (2020) 17:170-94. doi: 10.1038/s41569-019-0260-8

48. Dhaun N, Webb DJ. Endothelins in cardiovascular biology and therapeutics. Nat Rev Cardiol. (2019) 16:491-502. doi: 10.1038/s41569-019-0176-3

49. Um J-Y, Chung H-S, Song M-Y, Shin H-D, Kim H-M. Association of interleukin-1 $\beta$ gene polymorphism with body mass index in women. Clin Chem. (2004) 50:647-50. doi: 10.1373/clinchem.2003.025858

50. Zhang $\mathrm{C}, \mathrm{Wu} \mathrm{Z}, \mathrm{Li} \mathrm{J}-\mathrm{W}$, Zhao H, Wang G-Q. The cytokine release syndrome (CRS) of severe COVID-19 and interleukin-6 receptor (IL-6R) antagonist tocilizumab may be the key to reduce the mortality. Int J Antimicrob Agents. (2020) 20:533-4.

51. Dong E, Du H, Gardner L. An interactive web-based dashboard to track COVID-19 in real time. Lancet Infect Dis. (2020) 20:533-4. doi: 10.1016/S1473-3099(20)30120-1

52. Richardson S, Hirsch JS, Narasimhan M, Crawford JM, McGinn T, Davidson KW, et al. Presenting characteristics, comorbidities, and outcomes among 5700 patients hospitalized with COVID-19 in the New York City area. JAMA. (2020) 323:2052-9. doi: 10.1001/jama.2020.6775

53. Zhou F, Yu T, Du R, Fan G, Liu Y, Liu Z, et al. Clinical course and risk factors for mortality of adult inpatients with COVID-19 in Wuhan, China: a retrospective cohort study. Lancet. (2020) 395:1054-62. doi: 10.1016/S0140-6736(20)30566-3

54. Chen J, Qi T, Liu L, Ling Y, Qian Z, Li T, et al. Clinical progression of patients with COVID-19 in Shanghai, China. J Infect. (2020) 80:e1-6. doi: 10.1016/j.jinf.2020.03.004

55. Venkata C, Sampathkumar P, Afessa B, editors. Hospitalized patients with 2009 H1N1 influenza infection: the Mayo Clinic experience. Mayo Clin Proc. (2010) 85:798-805. doi: 10.4065/mcp.2010.0166

56. Morgan OW, Bramley A, Fowlkes A, Freedman DS, Taylor TH, Gargiullo $\mathrm{P}$, et al. Morbid obesity as a risk factor for hospitalization and death due to 2009 pandemic influenza A (H1N1) disease. PLoS ONE. (2010) 5:e9694. doi: 10.1371/journal.pone.0009694 
57. Lancet PSCJT. Body-mass index and cause-specific mortality in 900000 adults: collaborative analyses of 57 prospective studies. Lancet. (2009) 373:1083-96. doi: 10.1016/S0140-6736(09)60318-4

58. Zheng W, McLerran DF, Rolland B, Zhang X, Inoue M, Matsuo K, et al. Association between body-mass index and risk of death in more than 1 million Asians. N Engl J Med. (2011) 364:719-29. doi: 10.1056/NEJMoa10 10679

59. Murugan A, Sharma G. Obesity and respiratory diseases. Chron Respir Dis. (2008) 5:233-42. doi: 10.1177/1479972308096978

60. Steele RM, Finucane FM, Griffin SJ, Wareham NJ, Ekelund U. Obesity is associated with altered lung function independently of physical activity and fitness. Obesity. (2009) 17:578-84. doi: 10.1038/oby.2008.584

61. Falagas M, Athanasoulia A, Peppas G, Karageorgopoulos DE. Effect of body mass index on the outcome of infections: a systematic review. Obes Rev. (2009) 10:280-9. doi: 10.1111/j.1467-789X.2008.00546.x
62. Chang TH, Chou CC, Chang LYJOR. Effect of obesity and body mass index on coronavirus disease 2019 severity: a systematic review and meta-analysis. Obes Rev. (2020) 21:e13089. doi: 10.1111/obr.13089

Conflict of Interest: The authors declare that the research was conducted in the absence of any commercial or financial relationships that could be construed as a potential conflict of interest.

Copyright (C) 2021 Poly, Islam, Yang, Lin, Jian, Hsu and Jack Li. This is an open-access article distributed under the terms of the Creative Commons Attribution License (CC $B Y)$. The use, distribution or reproduction in other forums is permitted, provided the original author(s) and the copyright owner(s) are credited and that the original publication in this journal is cited, in accordance with accepted academic practice. No use, distribution or reproduction is permitted which does not comply with these terms. 